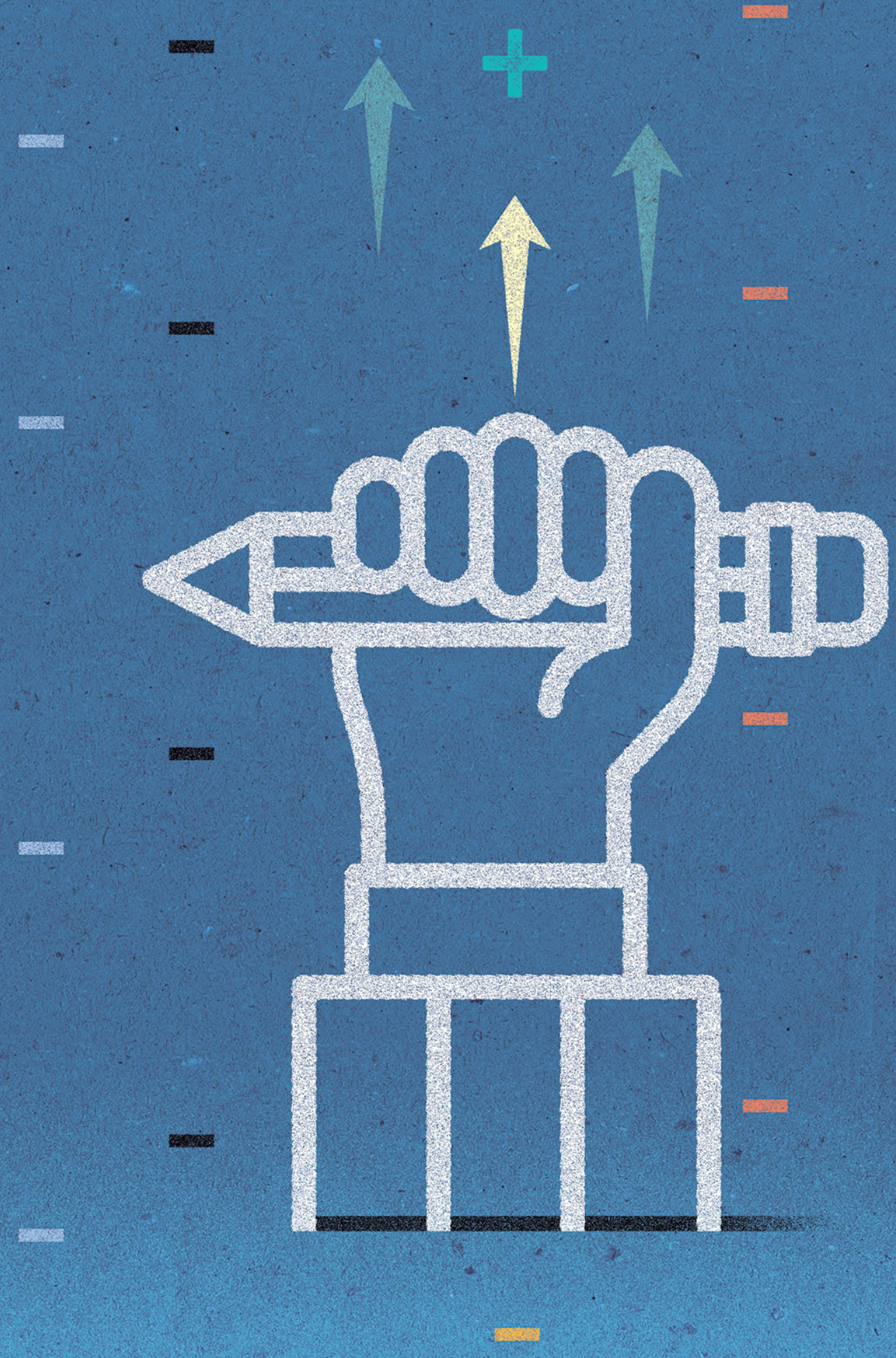




\title{
O novo marco legal de ciência, tecnologia e inovação no Brasil: desafios para a universidade
}

\author{
The new legal framework for science, \\ technology and innovation in Brazil: \\ challeges for universities
}

\author{
Ana Moria Nunes Gimenez* \\ Maria Beatriz Machado Bonacelli** \\ Marta Delpino Bambini***
}

\begin{abstract}
Resumo
Este artigo promove uma reflexão sobre a evolução da legislação brasileira relacionada à Ciência, Tecnologia e Inovação (CT\&l), do ponto de vista das Universidades inseridas em um Sistema Nacional de Inovação. O estudo teve características empírico-teóricas e natureza qualitativa, buscando identificar os principais desafios que se colocam às Universidades para a assimilação do novo Marco Legal de CT\&l (MLCTI). Os resultados indicam que apenas a promulgação de novas leis não leva a uma mudança substancial no posicionamento dos atores envolvidos, incluindo as Universidades. Há que se compreender, para isso, as possibilidades abertas pelo MLCTI e desenvolver uma cultura e um ambiente institucional mais adequados ao novo contexto, estabelecendo pontes com o setor produtivo, a partir de diferentes estratégias e políticas.
\end{abstract}

Palavras-chave: Marco Regulatório, Universidades, Sistemas de Inovação, Transferência de Tecnologia..

\begin{abstract}
This article promotes a reflection on the evolution of Brazilian legislation related to Science, Technology and Innovation (CT\&I), from the point of view of Universities inserted in a National Innovation System. The study had empirical-theoretical characteristics and qualitative nature, seeking to identify the main challenges imposed on Universities for the assimilation of the new CT\&I Legal Framework (MLCTI). The results indicate that the enactment of new laws alone does not lead to a substantial change in the positioning of the actors involved, including Universities. To this end, it is necessary to understand the possibilities opened by the MLCTI and to develop a culture and institutional environment better suited to the new context, establishing bridges with the productive sector, based on different strategies and policies.
\end{abstract}

Keywords: Regulatory Framework, Universities, Systems of Innovation, Technology Transfer.

\footnotetext{
* Doutora em Política Científica e Tecnológica pela Universidade Estadual de Campinas (DPCT/IG/UNICAMP). Pós-doutoranda no DPCT/IG/UNICAMP; bolsista CAPES/BRAIL pelo Instituto Nacional de Ciência e Tecnologia em Políticas Públicas, Estratégias e Desenvolvimento - INCT/PPED. E-mail: anamarianunesgimenez@gmail.com

** Doutora em Ciências Econômicas pela Université des Sciences Sociales de Toulouse, França. Professora Livredocente do Departamento de Política Científica e Tecnológica da Universidade Estadual de Campinas (DPCT/IG/ UNICAMP). E-mail: bia@ige.unicamp.br

*** Doutoranda no Departamento de Política Científica e Tecnológica da Universidade Estadual de Campinas (DPCT/IG/UNICAMP). Analista de Transferência de Tecnologia na Embrapa Informática Agropecuária, em Campinas/SP. E-mail: martha.bambini@embrapa.br
} 


\section{INTRODUÇÃO}

Nos países em desenvolvimento, as universidades públicas e os institutos públicos de pesquisa costumam ser os principais locus das pesquisas nacionais, o que torna cada vez mais relevante a criação de um arcabouço legal e de estruturas próprias para fomento e facilitação das pontes entre a academia e a sociedade, especialmente com o setor industrial, com vistas à promoção das atividades de P\&D e de inovação, (WIPO, 2010), levando-se em consideração que o locus preferencial da inovação é a empresa. Essas interações dependem da existência de estruturas de suporte, como recursos financeiros e humanos, políticas de incentivo e de apoio ao desenvolvimento de novas tecnologias e conhecimento, políticas de financiamento e fomento, políticas de propriedade intelectual. Além disso, também é necessária a criação de uma cultura favorável à proatividade da comunidade acadêmica frente a esse novo arcabouço e dinâmicas concebidas. $O$ estabelecimento dessas estruturas é importante não apenas para profissionalizar a $\mathrm{s}$ a tividades $\mathrm{d}$ e $\mathrm{p}$ roteção, a nálise e $\mathrm{v}$ aloração t ecnológica, como também para os processos negociais e para estimular e facilitar a criação de um ambiente no qual a transferência de tecnologia, o espírito empreendedor e a valorização da criatividade e dos direitos à ela relacionados possam gerar círculos virtuosos de conhecimento e inovação.

Sendo assim, o objetivo deste trabalho é o de promover uma reflexão sobre os desafios que se colocam para a a ssimilação d o n ovo Marco Legal de CT\&I - implementado pela lei n. 13.243/2016, com foco especial na atuação das Universidades Públicas, que efetivamente exercem atividades de ensino e pesquisa. Para tanto, foi realizada uma pesquisa empírica-documental sustentada por um arcabouço conceitual que tem o progresso técnico e a dinâmica da inovação como motores do desenvolvimento econômico e social. Por meio de buscas on-line foram identificados artigos de opinião, notícias, relatórios técnicos, legislação etc. Os dados são provenientes de diferentes fontes - repositórios institucionais, jornais (de grande circulação ou de entidades e associações científicas e d e fomento à p esquisa e à inovação), entre outros, bem como de diferentes atores - formuladores de políticas, técnicos, cientistas, juristas e outros. Devido à amplitude da temática e dos resultados obtidos, optamos por uma abordagem mais suscinta, com foco na evolução do marco legal da CT\&l, e na identificação de gargalos e desafios para a sua assimilação pelas universidades.

Além desta introdução, o artigo apresenta outras quatro partes, que abordam, respectivamente: breves considerações sobre o SNI brasileiro, suas forças e fragilidades; apresentação e análise, não exaustivas, do arcabouço jurídico da inovação no Brasil, bem como das principais inovações introduzidas pela Emenda Constitucional 85/2015 e pelo novo Marco Legal de CT\&I (MLCTI) - implementado pela lei n. 13.243/2016 e Decreto n. 9.283/2018; reflexões sobre os desafios que se colocam para a incorporação do MLCTI às práticas rotineiras das atividades inovativas das Universidades Públicas brasileiras; e, finalmente, considerações finais. 


\section{PARTICULARIDADES DO SISTEMA DE INOVAÇĀO BRASILEIRO: UMA BREVE EXPLANAÇÃO}

Arrocena e Sutz (2000) afirmam que os sistemas de inovação latino-americanos, em geral, são fracos ou incompletos e que as razões não estão apenas nas deficiências internas do próprio sistema, mas nos valores, econômico e social, que historicamente têm sido atribuídos aos conhecimentos endógenos e à inovação. Segundo os autores, em países desenvolvidos e com sistemas de inovação maduros parece existir um grau bastante grande (e generalizado) de consenso acerca da importância econômica e política dos papéis da ciência e da tecnologia para a aumento das capacidades nacionais, algo que falta na América Latina.

Suzigan e Albuquerque (2011, p. 17), por sua vez, comentam que o Brasil enfrenta significativas dificuldades para a mobilização de "contingentes de pesquisadores, cientistas e engenheiros em proporções semelhantes às dos países mais desenvolvidos" e as empresas se envolvem pouco com atividades de inovação. Entre os motivos desse quadro estão o tardio processo de industrialização e a forma como foi conduzido, assim como a tardia criação de instituições de educação superior e de instituições monetárias e financeiras, elementos que podem explicar, pelo menos em parte, os limites do nosso sistema de inovação, como também a fraca articulação com o setor produtivo.

Segundo Mazzucato e Penna (2016), o Estado brasileiro deve adotar uma nova abordagem para a construção de uma política de inovação estratégica e eficiente que, sem deixar de considerar os pontos fortes e fracos do sistema de inovação brasileiro, coloque a inovação no centro da política de desenvolvimento econômico, conectando as políticas de natureza econômica, conduzidas pelo Ministério da Fazenda às promovidas pelo Ministério da Ciência, Tecnologia, Inovações e Comunicações (MCTIC). Essa nova abordagem foi chamada de política orientada por missões ("mission-oriented"). "As políticas orientadas por missões podem ser definidas como políticas públicas sistêmicas que se baseiam em conhecimentos de fronteira para atingir metas específicas ou 'ciência grande implantada para enfrentar problemas grandes"' (MAZZUCATO; PENNA, 2016, p. 6), tendo em vista que a existência de missões bem definidas fornece um senso de direção e orientação a todos os atores que integram o sistema de inovação, favorecendo sua evolução, amadurecimento e, consequentemente, melhoria da sua capacidade de resposta às demandas da sociedade.

Em que pese a existência de instituições-chave indispensáveis à conformação dos quatro tipos de subsistemas necessários, quais sejam: o subsistema de educação e pesquisa; o subsistema de produção e inovação; o subsistema de financiamento público e privado; e o subsistema de políticas e regulação, existem importantes fragilidades que obstam a evolução do SNI brasileiro (MAZZUCATO; PENNA, 2016). No Quadro 1 foram sintetizadas as principais fraquezas ou fragilidades do SNI brasileiro: 
Quadro 1 - Fraquezas do SNI brasileiro

\begin{tabular}{|c|}
\hline Fraquezas \\
\hline $\begin{array}{l}\text { Política CT\&l apresenta-se mais como bandeira da comunidade científica e menos como política } \\
\text { estratégia do Estado brasileiro. }\end{array}$ \\
\hline $\begin{array}{l}\text { Inexistência de uma agenda estratégica consistente e sustentável, a longo prazo, que dê coerência às } \\
\text { políticas públicas realizadas pelas diferentes instituições públicas e que oriente a pesquisa científica e } \\
\text { aos agentes privados em seus esforços de inovação. }\end{array}$ \\
\hline $\begin{array}{l}\text { Entraves jurídicos e institucionais à inovação: gargalos de coordenação; gargalos de sinergia nas relações } \\
\text { público-privadas; gargalos de aprendizado e experimentação na política; gargalos na seletividade da } \\
\text { política. }\end{array}$ \\
\hline $\begin{array}{l}\text { Fragmentação e antagonismo entre os subsistemas de educação e pesquisa e de produção e inovação: } \\
\text { por exemplo, agendas de pesquisa desconectadas com as necessidades da sociedade; falta de demanda, } \\
\text { pelo setor industrial, do conhecimento produzido na academia; baixa propensão para inovar do } \\
\text { subsistema de produção e inovação. }\end{array}$ \\
\hline $\begin{array}{l}\text { Ineficiência do subsistema de política e regulação, especialmente, com a sobreposição de } \\
\text { responsabilidades, descontinuidade dos investimentos e de programas, burocracia excessiva, entre }\end{array}$ \\
\hline
\end{tabular}

Fonte: elaborado pelas autoras a partir de Mazzucato e Penna (2016); Pacheco (2018) e Coutinho e Mouallem (2018).

Em palestra ministrada na Universidade Estadual de Campinas, em agosto de 2018, Carlos Américo Pacheco afirmou que uma das mais importantes fragilidades do SNI brasileiro reside na grande dificuldade para definição das prioridades, bem como para coordenar as ações de governo (especialmente os orçamentos atrelados às políticas e aos diferentes ministérios envolvidos) e para interagir com outros atores do sistema de inovação. O MCTIC, segundo ele, encontra-se isolado das outras áreas do governo, além de deter baixa capacidade de coordenação, o que torna extremamente difícil legitimar mudanças sensíveis na distribuição dos recursos. Desse modo, "o ativismo estatal está muito mais focado na criação de instrumentos, especialmente pela via legislativa, do que em estratégias de ação" (PACHECO, 2018)¹.

Coutinho e Mouallem (2018), por seu turno, afirmam que os entraves jurídicos e institucionais à inovação no Brasil, que os autores chamam de gargalos, seriam os seguintes: gargalos de coordenação - insuficiente coordenação entre os órgãos públicos - tanto entre as instituições gestoras do fomento, como as de controle; gargalos de sinergia nas relações público-privadas - desarticulação e descompasso nas interações entre o setor público e o privado ("fragilidade da relação triangular entre Estado, empresas e universidades); gargalos de aprendizado e experimentação na política - a capacidade de coordenação deve ser constantemente revisada e aperfeiçoada; e gargalos na seletividade da política - dificuldade para realizar escolhas e priorizar setores mais intensivos em inovação e traçar objetivos definidos, com vistas a evitar a pulverização de recursos. Para Buainain, Corder e Bonacelli (2018, p. 42), embora o SNI brasileiro seja robusto e complexo,

é um sistema que não tem densidade e nem amplitude para apoiar e viabilizar processos de inovação mais amplos, nas pequenas e médias empresas, e para adensar e elevar a importância da inovação e agregação de valor nas cadeias de valor nas quais o país conta com empresas líderes competitivas. É também um sistema 
desequilibrado e concentrado regionalmente, que sofre descontinuidades que caracterizam as políticas públicas no país, vinculadas tanto às flutuações da conjuntura econômica como às mudanças de governos, que ainda não assumiram que as políticas de CT\&l são intervenções de médio e longo prazo e que as modificam em função de conveniências de curto prazo.

Em estudo relativo a políticas de inovação do Brasil, Argentina e China e capacidades estatais comparadas, Castro (2016) concluiu que no Brasil, em que pese o Plano Brasil Maior (PBM), instituído pelo Decreto no 7.540/2011, tenha estabelecido um sistema de gestão para a integração das ações governamentais voltadas às políticas industrial, tecnológica e de comércio exterior, na prática, "as coordenações sistêmicas parecem atuar mais em aconselhamento e indicações de políticas que na efetiva formulação e articulação de políticas" (CASTRO, 2016, p. 18).

Essas fragilidades e deficiências chamam atenção para a necessidade de desenvolvimento e melhoria das capacidades estatais ${ }^{2}$, bem como para a transformação das instituições públicas para que o Estado brasileiro possa fazer frente aos desafios que se colocam para a consolidação de seu Sistema Nacional de Ciência, Tecnologia e Inovação. Dessa forma, um arcabouço institucional que estimule e facilite o aprendizado contínuo, as interações e relacionamentos entre as organizações que desenvolvem novos conhecimentos e inovações, garantindo os direitos de titularidade e propriedade intelectual dos ativos gerados, é parte essencial desse processo.

\section{A CONSTRUÇÃO DO NOVO MARCO LEGAL DE CT\&I NO BRASIL}

O arcabouço jurídico da inovação no Brasil inclui um número considerável de normas jurídicas -portarias ministeriais, leis, decretos, etc. - referentes, principalmente à Política Industrial e de Comércio Exterior, aos incentivos à inovação tecnológica no ambiente produtivo, aos incentivos fiscais, às parcerias público-privadas, compras e contratações, e atividades de ciência, tecnologia e inovação (CT\&l) no país. A Lei de Inovação (Lei no 10.973/2004) e o seu decreto regulamentador (Decreto n 5.563/2005), concederam eficácia aos artigos 218 e 219 da Constituição Federal brasileira que tratam da ciência e da tecnologia. Esse arcabouço jurídico-institucional foi especificamente criado para incentivar a inovação e a pesquisa científica no ambiente produtivo, com vistas à autonomia tecnológica e ao desenvolvimento industrial do País. O Quadro 2 apresenta, sinteticamente, esses marcos. 
Quadro 2 - Evolução do Arcabouço Jurídico-Institucional relativo à Ciência, Tecnologia e Inovação no país

\begin{tabular}{|c|c|c|}
\hline Ano & Marco Regulatório & Propósito \\
\hline $\begin{array}{l}\text { 1996-1998; } \\
2007\end{array}$ & $\begin{array}{l}\text { Propriedade } \\
\text { Intelectual }\end{array}$ & $\begin{array}{l}\text { Lei no 9.279/1996 (Propriedade Industrial); Lei no 9.456/1997 } \\
\text { (Cultivares); Lei no 9.609/1998 (Programa de computador); Lei } \\
\text { n 9.610/1998 (Direitos Autorais e Conexos); Lei nº 11.484/2007 } \\
\text { (Topografia de Circuito Integrado). }\end{array}$ \\
\hline 1999 & $\begin{array}{l}\text { Fundos Setoriais de } \\
\text { Ciência e Tecnologia }\end{array}$ & $\begin{array}{l}\text { São instrumentos de financiamento de projetos de pesquisa, } \\
\text { desenvolvimento e inovação no País. O primeiro foi o CT Petro, } \\
\text { criado para estimular a inovação na cadeia produtiva do setor } \\
\text { de petróleo e gás natural, a formação e qualificação de recursos } \\
\text { humanos, bem como parcerias entre empresas e universidades, } \\
\text { instituições de ensino superior ou centros de pesquisa. }\end{array}$ \\
\hline $2003-2004$ & $\begin{array}{l}\text { Política Industrial, } \\
\text { Tecnológica e de } \\
\text { Comércio Exterior }\end{array}$ & $\begin{array}{l}\text { Foi concebida para aumentar a eficiência da estrutura produtiva, } \\
\text { a capacidade de inovação das empresas brasileiras e expansão } \\
\text { das exportações. }\end{array}$ \\
\hline 2004 & $\begin{array}{l}\text { Lei de Inovação } n^{\circ} \\
10.973 / 2004\end{array}$ & $\begin{array}{l}\text { Foi concebida para incentivar a inovação e a pesquisa científica } \\
\text { e tecnológica, especialmente no ambiente produtivo, mas sob } \\
\text { a concepção de um SNI. Revelou-se uma PPP (Parceria Público- } \\
\text { Privada), com a intenção de capacitar agentes públicos e } \\
\text { privados para a promoção da inovação no país. }\end{array}$ \\
\hline 2005 & $\begin{array}{l}\text { Decreto } n^{\circ} \\
5.563 / 2005\end{array}$ & Regulamentou a Lei de Inovação (Lei no 10.973/2004). \\
\hline 2005 & $\begin{array}{l}\text { Lei de Incentivos } \\
\text { Fiscais } \mathrm{n}^{\circ} \\
11.196 / 2005\end{array}$ & $\begin{array}{l}\text { Também conhecida como Lei do Bem, dispôs sobre Incentivos } \\
\text { fiscais para a inovação tecnológica. }\end{array}$ \\
\hline $2006(\ldots)$ & $\begin{array}{l}\text { Leis Estaduais de } \\
\text { Inovação }\end{array}$ & $\begin{array}{l}\text { Entre os primeiros estados a legislarem estão: Amazonas (2006); } \\
\text { São Paulo (2008), Rio de Janeiro (2008), Minas Gerais (2008), } \\
\text { Bahia (2008), Pernambuco (2008), Ceará (2008), Mato Grosso } \\
\text { (2008), entre outros. }\end{array}$ \\
\hline $2007-2010$ & $\begin{array}{l}\text { Ciência, Tecnologia } \\
\text { e Inovação para o } \\
\text { Desenvolvimento } \\
\text { Nacional: Plano de } \\
\text { Ação (PACTI) 2007- } \\
\text { 2010) }\end{array}$ & $\begin{array}{l}\text { Considerado o principal documento de planejamento do } \\
\text { Governo Federal para a ciência, tecnologia e inovação no } \\
\text { período } 2007-2010 \text {. Voltou-se, especialmente, à definição de } \\
\text { prioridades estratégicas, inciativas, ações e programas de } \\
\text { estímulo à P,D\&l nas empresas, entre outros objetivos. }\end{array}$ \\
\hline $2012-2015$ & $\begin{array}{l}\text { Estratégia Nacional } \\
\text { de Ciência, } \\
\text { Tecnologia e } \\
\text { Inovação (ENCTI) }\end{array}$ & $\begin{array}{l}\text { A ENCTI deu continuidade e aprofundou o Plano de Ação em } \\
\text { Ciência, Tecnologia e Inovação 2007-2010 (PACTI). }\end{array}$ \\
\hline 2015 & $\begin{array}{l}\text { Emenda } \\
\text { Constitucional } n^{\circ} 85 \\
\text { de } 26 \text { de fevereiro de } \\
2015 \text { (EC 85/2015) }\end{array}$ & $\begin{array}{l}\text { Alterou e adicionou dispositivos na Constituição Federal para } \\
\text { atualizar o tratamento das atividades de ciência, tecnologia e } \\
\text { inovação. }\end{array}$ \\
\hline 2016 & $\begin{array}{l}\text { Lei no } 13.243 \text {, de } 11 \\
\text { de janeiro de } 2016 \text { - } \\
\text { Novo Marco Legal de } \\
\text { Ciência, Tecnologia e } \\
\text { Inovação (MLCTI) }\end{array}$ & $\begin{array}{l}\text { Dispôs sobre estímulos ao desenvolvimento científico, à pesquisa, à } \\
\text { capacitação científica e tecnológica eà inovação, tendo alterado nove leis, } \\
\text { especialmente, a Lei de Inovação (2004). }\end{array}$ \\
\hline 2018 & $\begin{array}{l}\text { Decreto } 9.283 \text {, de } 7 \\
\text { de fevereiro de } 2018\end{array}$ & Regulamentou o conjunto de alterações introduzidas pelo Novo MLCTI. \\
\hline
\end{tabular}

Fonte: elaboração própria. 
Neste estudo discutimos algumas das inovações introduzidas no arcabouço jurídico da ciência, tecnologia e inovação, especificamente, por duas normas: a Emenda Constitucional no 85 de 26 de fevereiro de 2015 (EC 85/2015); o Novo Marco Legal da Ciência, Tecnologia e Inovação (Lei n 13.243, de 11 de janeiro de 2016) e seu Decreto regulamentador ( $n^{\circ} 9.283 / 2018$ ).

\section{EVENTOS PREPARATÓRIOS À INSTAURAÇÃO DE UM NOVO MARCO LEGAL}

O Novo Marco Legal é o resultado de discussões iniciadas no ano de 2011, conforme apresentado no Quadro 3, a seguir.

Quadro 3 - Discussões prévias à aprovação do PL n.2177

\begin{tabular}{|c|c|}
\hline Período & Descrição dos Fatos Ocorridos \\
\hline $04 / 2011$ & $\begin{array}{l}\text { A audiência pública da Comissão de Ciência e Tecnologia, Comunicação e Informática da } \\
\text { Câmara dos Deputados, para subsidiar o Projeto de Lei. }\end{array}$ \\
\hline $08 / 2011$ & $\begin{array}{l}\text { Apresentação do Projeto de Lei } n^{\circ} .2177 / 2011 \text { na Câmara de Deputados para instituir o } \\
\text { Código Nacional de Ciência, Tecnologia e Inovação no Brasil. }\end{array}$ \\
\hline $10 / 2013$ & $\begin{array}{l}\text { Última audiência pública antes da votação do Projeto de Lei 2177/11, na Câmara dos } \\
\text { Deputados. }\end{array}$ \\
\hline $05 / 2014$ & $\begin{array}{l}\text { Pedidos recorrentes de parlamentares ligados à área de CT\&I para inclusão do Projeto de } \\
\text { Lei (PL) } 2177 \text { na pauta de votações do Plenário da Câmara dos Deputados, fruto de um } \\
\text { grupo de trabalho formado pela SBPC, ABC, CONSECTI e CONFAP. }\end{array}$ \\
\hline $06 / 2014$ & $\begin{array}{l}\text { Reunião de representantes do setor científico e tecnológico com parlamentares, na } \\
\text { Câmara dos Deputados, para tratar mais uma vez sobre o novo marco legal para o setor. }\end{array}$ \\
\hline $07 / 2015$ & $\begin{array}{l}\text { Redação final aprovada e assinada pelo Relator do PL 2177/2011; encaminhamento ao } \\
\text { Senado Federal, onde o Projeto recebeu nova numeração (PL 77/2015). }\end{array}$ \\
\hline 01/10/2015 & $\begin{array}{l}\text { A Medida Provisória (MP) 694/2015 suspendeu os efeitos dos artigos } 19,19 \mathrm{~A} \text { e } 26 \text { da Lei } \\
\text { do Bem (a partir de 2016), a qual permitia que empresas deduzissem, de seus impostos } \\
\text { anuais, os investimentos em P\&D\&l. É um incentivo importante e que motivou o } \\
\text { desenvolvimento de centros de P\&D de multinacionais no país. No entanto, a MP perdeu } \\
\text { o efeito em } 08 \text { de março de } 2016, \text { por não ter sido convertida em lei, no prazo de } 120 \text { dias } \\
\text { da sua publicação ( } 60 \text { dias, prorrogáveis por mais } 60 \text { dias). }\end{array}$ \\
\hline $24 / 10 / 2015$ & $\begin{array}{l}\text { Aprovação por unanimidade, nas comissões de Assuntos Econômicos (CAE) e de Ciência e } \\
\text { Tecnologia (CCT) do Senado Federal, do Projeto de Lei da Câmara (PLC) n 77/2015, antigo } \\
\text { Projeto de Lei (PL) 2177/2011, que altera e aperfeiçoa nove legislações que regulamentam } \\
\text { as atividades de ciência, tecnologia e inovação (CT\&l). }\end{array}$ \\
\hline $01 / 12 / 2015$ & $\begin{array}{l}\text { Atraso na votação da PL 77/2015 em função da votação do déficit do Governo, do evento } \\
\text { COP } 21 \text { na França (os relatores do projeto estariam na comitiva do governo). }\end{array}$ \\
\hline 08/12/2015 & $\begin{array}{l}\text { Com o intuito de acelerar a aprovação do chamado Código de Ciência, Tecnologia e } \\
\text { Inovação (projeto de lei no 77/2015) no plenário do Senado Federal, e, em seguida, a } \\
\text { sanção presidencial, } 17 \text { instituições nacionais, dentre elas, a Sociedade Brasileira para o } \\
\text { Progresso da Ciência (SBPC), lançaram um documento intitulado "Aliança em Defesa do } \\
\text { Novo Marco Legal de CT\&l". }\end{array}$ \\
\hline 09/12/2015 & $\begin{array}{l}\text { Aprovação, no Senado, do PL } 77 / 15 \text {, que institui o Código de Ciência, Tecnologia e } \\
\text { Inovação e promove uma série de ações para o incentivo à pesquisa, à inovação e ao } \\
\text { desenvolvimento científico e tecnológico. Matéria enviada à análise e sanção presidencial. }\end{array}$ \\
\hline $18 / 12 / 2015$ & $\begin{array}{l}\text { Formação de uma Aliança em Defesa do Marco Legal da CT\&I para conscientização sobre } \\
\text { a aprovação do PLC 77/2015 sem vetos. }\end{array}$ \\
\hline
\end{tabular}

Fonte: elaborado pelas autoras a partir de buscas realizadas nas seguintes bases: Agência ABIPTI, Jornal da Ciência/SBPC, ANPEI, Senado Federal, Câmara dos Deputados. 
Pacheco, Bonacelli e Foss (2017, p. 214) explicam que a ideia original era o estabelecimento de Código Nacional de CT\&l,

que contemplava a robustez e a complexidade de um compêndio de leis relacionadas à CT\&l. Após rodadas de audiências e consultas públicas sobre o Projeto de Lei 2177 de 2011, a proposta de um código foi abandonada em favor de uma estratégia mais pontual que visava modificar a Constituição Federal e revisar a Lei de Inovação, bem como alterar outras normas relativas à CT\&l. Essa estratégia resultou na Emenda Constitucional n. 85, de 26 de fevereiro de 2015, e na Lei n. 13.243, de 12 de janeiro de 2016, que passou a ser conhecida por "Marco Legal da CT\&I" (MLCTI).

Nota-se, portanto, que o processo de construção do Novo Marco iniciou em abril de 2011, com audiência pública na Câmara dos Deputados, sendo fruto de discussões e preocupações que envolveram não apenas o Poder Legislativo, como também a comunidade científica nacional, bem como organizações da sociedade civil.

\section{AS ALTERAÇÕES CONSTITUCIONAIS: A EC N. 85/2015}

A Emenda Constitucional no 85 de 26 de fevereiro de 2015 (EC 85/2015) preparou o caminho para as regras do Novo Marco, incorporando na Constituição Federal um novo direcionamento para o tratamento da temática da ciência, tecnologia e inovação. A EC 85/2015 permitiu a flexibilização do orçamento, permitindo a realocação de recursos quando o objetivo for a viabilização de projetos de ciência, tecnologia e inovação, conforme transcrição a seguir:

\section{§ $5^{\circ} \mathrm{A}$ transposição, o remanejamento ou a transferência de recursos de uma categoria de programação para outra poderão ser admitidos, no âmbito das atividades de ciência, tecnologia e inovação, com o objetivo de viabilizar os re- sultados de projetos restritos a essas funções, mediante ato do Poder Executivo, sem necessidade da prévia autorização legislativa prevista no inciso VI deste artigo (BRASIL, 2015, grifo nosso).}

Pedrosa (2018, p. 10) explica que esse novo permissivo legal representa uma exceção ao princípio da proibição de estorno, expressamente previsto no art. 167, VI da CF. Em outras palavras, recursos previstos na Lei Orçamentária podem ser direcionados/remanejados/transpostos para outras áreas, orgãos etc., com o intuito de viabilizar projetos estritamente ligados à atividades de ciência, tecnologia e inovação, bastando, para tanto, a edição de um Decreto do Poder Executivo (exceção ao princípio da legalidade, já que essa realocação depende de lei).

A Emenda também alterou o "sistema de repartição de competências constitucionais, incluindo ciência e tecnologia no rol das competências comuns e concorrentes" (PEDROSA, 2018, p. 11). Sendo assim, com a EC 85/2015 os incisos V, do artigo 23 e o inciso IX, do artigo 24, passaram a ter a seguinte redação (as partes em negrito foram acrescentadas pela Emenda):

Art. 23. É competência comum da União, dos Estados, do Distrito Federal e dos Municípios: 
[...] V - proporcionar os meios de acesso à cultura, à educação, à ciência, à tecnologia, à pesquisa e à inovação;

Art. 24. Compete à União, aos Estados e ao Distrito Federal legislar concorrentemente sobre:

[...] IX - educação, cultura, ensino, desporto, ciência, tecnologia, pesquisa, desenvolvimento e inovação (BRASIL, 1988; 2015, grifo nosso).

A competência comum (cumulativa), prevista no artigo 23 da Constituição Federal, significa que tanto a União, quanto os Estados, o Distrito Federal e os Municípios podem legislar sobre as matérias previstas no rol do referido artigo. No caso da competência concorrente (artigo 24), caberá à União estabelecer as regras gerais, estando os demais entes federativos (exceto os Municípios) autorizados a legislarem sobre as mesmas matérias, com observância da regra geral estabelecida pela União.

No capítulo que trata da Educação, Cultura e do Desporto, foi definido que o Poder Público concederá apoio financeiro às atividades de pesquisa, de extensão e de estímulo e fomento à inovação realizadas não apenas por universidades, mas também por instituições de educação profissional e tecnológica (artigo 213, § 2º. No capítulo que trata da Ciência, Tecnologia e Inovação foi introduzida uma das mais importantes alterações promovidas pela Emenda n 85, ou seja, a institucionalização do Sistema Nacional de Ciência, Tecnologia e Inovação (SNCTI), ao acrescentar no corpo normativo da Constituição Federal os artigos 219-A e 2019-B.

Art. 219-A. A União, os Estados, o Distrito Federal e os Municípios poderão firmar instrumentos de cooperação com órgãos e entidades públicos e com entidades privadas, inclusive para o compartilhamento de recursos humanos especializados e capacidade instalada, para a execução de projetos de pesquisa, de desenvolvimento científico e tecnológico e de inovação, mediante contrapartida financeira ou não financeira assumida pelo ente beneficiário, na forma da lei.

Art. 219-B. O Sistema Nacional de Ciência, Tecnologia e Inovação (SNCTI) será organizado em regime de colaboração entre entes, tanto públicos quanto privados, com vistas a promover o desenvolvimento científico e tecnológico e a inovação (BRASIL, 1988, 2015).

A EC 85/2015 também estabeleceu que o Estado deverá proporcionar tratamento prioritário à pesquisa básica e tecnológica; apoiar a formação de recursos humanos para atuarem nas áreas de ciência, pesquisa e tecnologia, inclusive por meio da extensão tecnológica; estimular o investimento empresarial em inovação; a articulação entre entes públicos e privados; entre outros (artigos 218 a 219-B), como também incluiu entre as competências do Sistema Único de Saúde (SUS), a incrementação do desenvolvimento científico e tecnológico e a inovação, no âmbito da sua área de atuação (artigo 200, inico V). Segundo o MCTIC, em face desse novo quadro normativo, o mérito da EC 85/2015 foi o de "conferir maior destaque às políticas de Estado relacionadas com o tema CT\&l, abrindo a oportunidade para uma regulamentação que possa conferir maior centralidade aos assuntos do setor pelos entes da Federação" (2017, p. 74). 


\section{A LEI N'. 13.243/2016: ENFIM UM NOVO MARCO LEGAL DA CIÊNCIA, TECNOLOGIA E INOVAÇÃO}

A Lei no 13.243/2016 (regulamentada pelo Decreto n 9.283/2018) promoveu alterações significativas no arcabouço jurídico da inovação (ao todo, nove leis foram alteradas) para que fosse possível introduzir o novo regramento legal, conforme listado no Quadro 4.

Quadro 4 - Leis alteradas pelo Novo Marco Legal

\begin{tabular}{|c|c|c|}
\hline \multicolumn{2}{|c|}{ Número da Lei } & \multirow{2}{*}{$\begin{array}{l}\text { Nome/Escopo da Lei } \\
\text { Lei de Inovação }\end{array}$} \\
\hline 1 & $\begin{array}{l}\text { Lei no } 10.973 \text {, de } 2 \text { de dezembro } \\
\text { de } 2004\end{array}$ & \\
\hline 2 & $\begin{array}{l}\text { Lei } n^{\circ} 6.815 \text {, de } 19 \text { de agosto } \\
\text { de } 1980\end{array}$ & Estatuto do Estrangeiro \\
\hline 3 & $\begin{array}{l}\text { Lei } n^{\circ} 8.666 \text {, de } 21 \text { de junho } \\
\text { de } 1993\end{array}$ & Lei de Licitações \\
\hline 4 & $\begin{array}{l}\text { Lei } n^{\circ} 12.462 \text {, de } 4 \text { de agosto } \\
\text { de } 2011\end{array}$ & Regime Diferenciado de Contratações Públicas - RDC \\
\hline 5 & $\begin{array}{l}\text { Lei } n^{\circ} 8.745 \text {, de } 9 \text { de dezembro } \\
\text { de } 1993\end{array}$ & $\begin{array}{l}\text { Relativa à contratação por tempo determinado para atender a } \\
\text { necessidade temporária de excepcional interesse público }\end{array}$ \\
\hline 6 & $\begin{array}{l}\text { Lei n'8.958, de } 20 \text { de dezembro } \\
\text { de } 1994\end{array}$ & $\begin{array}{l}\text { Relativa às relações entre as instituições federais de ensino superior e de } \\
\text { pesquisa científica e tecnológica e as fundações de apoio }\end{array}$ \\
\hline 7 & $\begin{array}{l}\text { Lei no } 8.010 \text {, de } 29 \text { de março } \\
\text { de } 1990\end{array}$ & $\begin{array}{l}\text { Relativa às importações de bens destinados à pesquisa científica e } \\
\text { tecnológica }\end{array}$ \\
\hline 8 & Lei $n^{\circ} 8.032$, de 12 de abril de 1990 & Isenção ou redução de impostos de importação \\
\hline 9 & $\begin{array}{l}\text { Lei } n^{\circ} 12.772 \text {, de } 28 \text { de dezembro } \\
\text { de } 2012\end{array}$ & $\begin{array}{l}\text { Relativa ao Plano de Carreiras e Cargos de Magistério Federal; e Carreira do } \\
\text { Magistério Superior }\end{array}$ \\
\hline
\end{tabular}

Fonte: elaboração própria.

A seguir, são apresentadas algumas das alterações e/ou inovações introduzidas pela Lei no 13.243/2016 (Novo MLCTI):

a) introdução do termo "inovação" ao nome das ICTs - Instituição Científica, Tecnológica e de Inovação (art. 2º, inciso IV da Lei n 10.973/2004 - Lei de Inovação); b) introdução do conceito de extensão tecnológica: "atividade que auxilia no desenvolvimento, no aperfeiçoamento e na difusão de soluções tecnológicas e na sua disponibilização à sociedade e ao mercado" (art. $2^{\circ}$, inciso XII da Lei no 10.973/2004 - Lei de Inovação);

c) permissão para que pesquisadores e docentes de ICTs públicas, em regime de dedicação exclusiva, exerçam atividade de pesquisa também no setor privado, com remuneração (art. 14-A da Lei no 10.973/2004 - Lei de Inovação);

d) concessão de licença não remunerada, a pesquisador público, para constituição de empresa cujo objeto de exploração esteja relacionado com a inovação (pelo 
prazo de três anos consecutivos, renováveis por igual período) (art. 15 da Lei nº 10.973/2004 - Lei de Inovação) - "pesquisador público: ocupante de cargo público efetivo, civil ou militar, ou detentor de função ou emprego público que realize, como atribuição funcional, atividade de pesquisa, desenvolvimento e inovação" (art. 2º, inciso VIII da Lei nº 10.973/2004 - Lei de Inovação);

e) aumento do número de horas que os docentes vinculados ao regime de dedicação exclusiva podem dedicar a atividades "esporádica de natureza científica ou tecnológica em assuntos de especialidade do docente, inclusive em polos de inovação tecnológica": passou de 120 horas para 416 horas anuais; 8 horas semanais (alteração no quadro de carreira do Magistério Federal, art. 21, inciso XII - Lei no 12.772/2012);

f) incorporação na Lei do conceito de "capital intelectual: conhecimento acumulado pelo pessoal da organização, passível de aplicação em projetos de pesquisa, desenvolvimento e inovação" (art. 2º, inciso XIV da Lei no 10.973/2004 - Lei de Inovação);

g) obrigatoriedade da instituição de uma política de inovação nas ICTs públicas, nos termos do artigo 15-A da Lei no 10.973/2004 - Lei de Inovação:

Art. 15-A. A ICT de direito público deverá instituir sua política de inovação, dispondo sobre a organização e a gestão dos processos que orientam a transferência de tecnologia e a geração de inovação no ambiente produtivo, em consonância com as prioridades da política nacional de ciência, tecnologia e inovação e com a política industrial e tecnológica nacional.

Parágrafo único. A política a que se refere o caput deverá estabelecer diretrizes e objetivos:

I - estratégicos de atuação institucional no ambiente produtivo local, regional ou nacional;

II - de empreendedorismo, de gestão de incubadoras e de participação no capital social de empresas;

III - para extensão tecnológica e prestação de serviços técnicos;

IV - para compartilhamento e permissão de uso por terceiros de seus laboratórios, equipamentos, recursos humanos e capital intelectual;

V - de gestão da propriedade intelectual e de transferência de tecnologia;

VI - para institucionalização e gestão do Núcleo de Inovação Tecnológica;

VII - para orientação das ações institucionais de capacitação de recursos humanos em empreendedorismo, gestão da inovação, transferência de tecnologia e propriedade intelectual;

VIII - para estabelecimento de parcerias para desenvolvimento de tecnologias com inventores independentes, empresas e outras entidades.

h) permissão para que os Núcleos de Inovação Tecnológica (NIT) possam atuar como Fundações de Apoio - autorização incluída no artigo 1요 $\S 8^{\circ}$ da Lei $n^{\circ}$ 8.958/1994 (que dispõe sobre as Fundações de Apoio). Além disso, acrescentado o 
artigo $2^{\circ}$, inciso VII da Lei n 10.973/2004 (Lei de Inovação) passou a ter a seguinte redação:

Fundação de apoio: fundação criada com a finalidade de dar apoio a projetos de pesquisa, ensino e extensão, projetos de desenvolvimento institucional, científico, tecnológico e projetos de estímulo à inovação de interesse das ICTs, registrada e credenciada no Ministério da Educação e no Ministério da Ciência, Tecnologia e Inovação, nos termos da Lei no 8.958, de 20 de dezembro de 1994, e das demais legislações pertinentes nas esferas estadual, distrital e municipal (grifo nosso).

Redação anterior:

VII - instituição de apoio - fundação criada com a finalidade de dar apoio a projetos de pesquisa, ensino e extensão e de desenvolvimento institucional, científico e tecnológico de interesse das IFES e demais ICTs, registrada e credenciada nos Ministérios da Educação e da Ciência e Tecnologia, nos termos da Lei no 8.958, de 20 de dezembro de 1994 (grifo nosso).

i) estímulo à internacionalização das ICTs, permitindo que atuem no exterior (art. $3^{\circ}$ - C, Lei no 10.973/2004 - Lei de Inovação);

j) dispensa de abertura de processo licitatório para celebração de contratos de transferência de licenciamentos, que poderão ser firmados diretamente (art. 60, § $2^{\circ}$ da Lei no 10.973/2004 - Lei de Inovação);

k) tratamento prioritário e simplificação dos procedimentos para importação e de desembaraço aduaneiro de bens, insumos, reagentes, peças e componentes a serem utilizados em pesquisa científica e tecnológica ou em projetos de inovação (Leis n 8.010/1990 e n 8.032/1990).

I) simplificação e uniformização dos procedimentos de prestação de contas dos recursos repassados (art. 27-A, da Lei nº 10.973/2004 - Lei de Inovação).

A Lei no 13.243/2016 foi sancionada pela Presidente da República com oito vetos, sendo cinco deles na proposta de aperfeiçoamento e ampliação dos benefícios da Lei de Inovação (10.973/2004). Os temas abrangidos pelos dispositivos vetados incluem, entre outros: isenção de incidência de contribuição previdenciária para as bolsas de estímulo à inovação concedidas aos alunos de graduação e pós-graduação, docentes e pesquisadores de universidades e instituições científicas e tecnológicas (ICTs) privadas (somente as bolsas concedidas por ICTs públicas estão isentas); isenção das importações de empresas para atender projetos de P\&D; possibilidade de inclusão, nos contratos firmados com ICTs, empresas, fundações de apoio, agências de fomento, de taxa de administração para cobertura de despesas operacionais e administrativas"; e a dispensa de licitação para contratação de micro, pequenas e médias empresas para prestarem serviços ou fornecerem bens elaborados com aplicação de conhecimento científico e tecnológico. Atualmente, encontra-se em tramitação, no Senado Federal, o Projeto de Lei $n^{\circ} 226 / 20165^{5}$, que propõe a recuperação integral da matéria original. 
Finalmente, o Decreto n 9.283, de 7 de fevereiro de 2018 (em 10 capítulos e 87 artigos), regulamentou o conjunto de alterações promovidas pelo Novo Marco. Dado à abrangência da matéria, foram selecionados alguns dos temas presentes no Decreto, sobre os quais são destacados dois novos conceitos introduzidos pelo Decreto no arcabouço jurídico da ciência, tecnologia e inovação brasileiro. O primeiro, é o conceito de ecossistema de inovação, nos termos do artigo 2., inciso ll, alínea "a":

ecossistemas de inovação - espaços que agregam infraestrutura e arranjos institucionais e culturais, que atraem empreendedores e recursos financeiros, constituem lugares que potencializam o desenvolvimento da sociedade do conhecimento e compreendem, entre outros, parques científicos e tecnológicos, cidades inteligentes, distritos de inovação e polos tecnológicos.

Embora não se trate de uma ideia nova, pois tem sido desenvolvida pela literatura especializada, sendo conhecida pelos que atuam nessa área, trata-se do seu enquadramento/reconhecimento oficial (formal), como um dos "ambientes promotores de inovação", previstos no artigo $2^{\circ}$, II.

O segundo, é o conceito de risco tecnológico (artigo 20, inciso III):"risco tecnológicopossibilidade de insucesso no desenvolvimento de solução, decorrente de processo em que o resultado é incerto em função do conhecimento técnico-científico insuficiente à época em que se decide pela realização da ação". É o reconhecimento da necessidade de tratamento diferenciado às atividades de CT\&l, dadas às suas especificidades e que requerem, portanto, monitoramento e avaliações que levem em conta essas questões. Sendo assim, em caso de não atingimento das metas estabelecidas, em face de problemas ligados aos riscos inerentes ao objeto, não haverá o dever de ressarcimento, nos termos do artigo 48, inciso I, do Decreto.

Cabe ressaltar que o impacto das mudanças propostas pelo novo MLCTI, mas também dos vetos à nova Lei ainda foram pouco sentidos, pois não basta uma lei ser promulgada - sua "instalação" não é automática. É necessário que seja compreendida e disseminada a ponto de integrar-se às práticas rotineiras. Portanto, a sua disseminação se dá pela aplicação e uso de suas diretrizes pelos atores do SNI, cada qual a sua maneira e possibilidades. Papel especial têm as agências de financiamento e de fomento à CT\&l, mas também os órgãos de controle, acompanhamento e avaliação. As universidades também têm um raio de manobra que possibilita a internalização do arcabouço e dos instrumentos legais e regulatórios da CT\&l, os quais, se bem empregados, podem mudar o perfil, a conduta e os impactos de suas ações e seu desempenho em ensino, pesquisa e extensão.

\section{UNIVERSIDADES E O NOVO MARCO LEGAL DE CT\&I: DESAFIOS PARA ASSIMILAÇÃO}

A partir da segunda metade do século XX, as atividades de transferência de tecnologia passaram a ganhar destaque e a ocorrer de forma estruturada e deliberada nos 
países desenvolvidos, onde, em geral, são vistas como fortemente importantes para o desenvolvimento técnico-econômico de uma nação.

No entanto, devido aos papéis clássicos da academia e da indústria, a transferência de tecnologia também pode envolver aspectos indesejáveis, pois existe uma lacuna cultural entre esses dois atores. Trata-se de um abismo que alguns estudiosos chamam de "o vale da morte", pois ambos são essencialmente diferentes, e essas diferenças, muitas vezes, podem ser conflitantes (WIPO, 2012, p. 4). Sendo assim, "o desafio da transferência tecnológica é o desafio de interligar essas duas culturas, de construir uma ponte sobre 'o vale da morte', que os separa" (WIPO, 2012, p. 4).

Desde a sua fundação, o objetivo final das universidades tem sido a criação de conhecimento, sua preservação e disseminação para o benefício das gerações vindouras. Autonomia e liberdade são duas condições fundamentais para a cultura acadêmica, cujo propósito é assegurar o seu compromisso com a disseminação do conhecimento, em seu aspecto mais amplo, sem distinções. A indústria, por outro lado, possui diferentes metas, sendo que a principal é gerar lucro próprio e, direta ou indiretamente, proporcionar divisas e riquezas para o país. Sendo assim, na indústria prepondera o foco em determinados produtos e campos de pesquisa, sob a lógica do controle e da propriedade. Portanto, um dos grandes desafios que se colocam para a relação academia-indústria é equilibrar os diferentes interesses: os interesses do público em geral - beneficiário dos produtos gerados pela academia - notadamente, a produção e disseminação do conhecimento e a formação de recursos humanos; e os interesses daqueles que participam do processo - indústria, universidade e pesquisador. Logicamente que, quando a indústria prospera são criados benefícios também à sociedade por meio da criação de empregos e do aquecimento da economia etc. (WIPO, 2012).

Nesse sentido, tanto a academia quanto a indústria servem à sociedade, mas enquanto o objetivo direto da indústria é a geração de riqueza, em primeiro lugar para os seus sócios, sendo o benefício público (sociedade) um subproduto desse objetivo, na academia, por outro lado, o benefício da sociedade é o objetivo central. "A tentativa de construir uma ponte sobre este'vale da morte', envolve a infiltração do pensamento empresarial na academia" (WIPO, 2012, p. 8). Ocorre que essa situação tem gerado desconforto e até mesmo resistência no seio da academia.

Slaughter e Leslie (1997), por exemplo, usam o termo "capitalismo acadêmico", para criticar a interiorização pela academia de valores e lógicas do mercado, que segundo os autores, podem comprometer e colocar em risco os seus próprios valores, a sua autonomia e o seu modus operandi. Para Florida (1999), a ideia das universidades como produtoras de tecnologia e motores do desenvolvimento regional é equivocada, pois, em última análise elas devem cumprir o seu papel de desenvolvedoras de talentos, não de tecnologia. Esses pontos de vista baseiam-se no temor de que a crescente ênfase de governos e dirigentes universitários nas interações e relacionamentos com a indústria, desenvolvimento de tecnologias patenteáveis e realização de transferência 
de tecnologia, possa provocar alterações nas agendas pesquisa, que passariam a ter enfoques mais utilitaristas, acirrariam a apropriação privada dos resultados da pesquisa, obstariam a disseminação do conhecimento, em vista da necessidade de sigilo, entre outros aspectos negativos.

De toda forma, há uma grande mudança em curso, tendo em vista que, no Brasil, as universidades públicas, como todo ente público que trabalha com ensino e pesquisa, foram obrigadas a criar em seu interior, instâncias, programas, projetos e diretrizes (formais e informais) para tratar da transferência de tecnologia e das relações universidade-sociedade - especialmente com empresas.

Sob a égide de uma economia baseada em conhecimento, da escassez de recursos financeiros para ensino e pesquisa, e da competição por mecanismos de fomento, entre outros, se intensificam os debates e as cobranças em torno das contribuições das pesquisas acadêmicas à sociedade, especialmente quando financiadas com recursos públicos. As universidades de pesquisa têm um papel importante nos Sistemas de Inovação dos países, pois formam recursos humanos, treinam pesquisadores, contribuem para ampliação dos estoques de conhecimento, prestam serviços, entre outras contribuições.

Trazendo essa discussão para o caso brasileiro, Gimenez (2017), que investigou a relação universidade-sociedade no Brasil e no exterior, concluiu que na universidade pública brasileira ainda imperam algumas visões contraditórias acerca da pertinência e da legitimidade dos envolvimentos com os diversos setores da sociedade, preponderando, em muitos casos, resistência às interações com empresas, ao patenteamento e à transferência de tecnologia, bem como posturas e preferências extensionistas que ainda denotam um ranço assistencialista. Arbix e Consoni (201, p. 205), por seu turno, afirmam que mesmo tendo ocorrido mudanças que impactaram positivamente as estruturas institucionais das universidades, favorecendo as ações de proteção à propriedade intelectual e de transferência de tecnologia, nota-se que

\begin{abstract}
a universidade brasileira permanece insulada e carece de canais de ligação capazes de viabilizar a estreita sintonia com os esforços que faz o país para se desenvolver. A realização desse debate, muitas vezes tomado falsamente como um ataque à autonomia universitária, é cada vez mais urgente. A universidade, no mundo todo, vive uma segunda revolução acadêmica. Ensino e pesquisa combinam-se agora com forte atuação de transferência de conhecimento para a sociedade. No Brasil, é urgente a necessidade de se ampliar a sinergia e os fluxos de conhecimento entre universidade e sociedade, determinantes para a absorção, a aprendizagem e a geração de inovação e tecnologia.
\end{abstract}

Segundo Pacheco (2018), o uso e implementação do arcabouço jurídico e legal relativo à CT\&l no país dependem fortemente das Fundações de Apoio à C\&T e das agências de fomento, que podem internalizar em seus programas, projetos e editais as novas normas, disseminando assim as novas diretrizes embutidas no quadro legal da CT\&I. Dessa forma, 
[...] não basta constar do texto da Lei que parcerias púbico-privadas promoverão ambientes propícios à inovação, mas sim é necessário o comprometimento dos atores envolvidos para que sejam criados os arranjos jurídico-institucionais necessários para instrumentalizar as parcerias almejadas (PACHECO; BONACELLI; FOSS, 2017, p. 214).

Junta-se a isso, a necessidade de uma outra postura do Direito Administrativo, capaz de também internalizar tais mudanças e tentativas de modernização do aparato jurídico, desfazendo entraves para a difusão de uma cultura em prol das atividades de inovação, as quais, pela sua natureza, envolvem riscos, incertezas e prazos mais longos para a maturação de projetos e investimentos. No entanto, não se trata de uma tarefa fácil, pois, em primeiro lugar, as regras jurídicas comumente não conseguem acompanhar a dinâmica social, ao contrário. É comum que estejam quase sempre defasadas em face da celeridade das mudanças, especialmente no campo do avanço tecnológico, mas não somente. A morosidade do processo legislativo, aliada à necessidade de estabilidade institucional e segurança jurídica explicam, em parte, esse processo de transformação mais lento, embora existam situações de fronteira, como é o caso do Código Civil, publicado em 2002, cuja tramitação perdurou por 27 anos.

Isso assume outros contornos quando se está no âmbito do Direito Público, tendo em vista que o regime jurídico-administrativo delineia-se em função de dois princípios fundantes, quais sejam: a supremacia do interesse público sobre o privado; e a indisponibilidade, pela Administração, dos interesses públicos, tendo em vista que seu comprometimento último é com o interesse geral da sociedade (BANDEIRA DE MELLO, 2018). Além disso, a Administração Pública, da qual fazem parte as ICTs públicas - como as universidades, as fundações, os institutos de pesquisa, bem como as agências de fomento e outros entes, que integram a administração pública indireta, também estão atreladas aos princípios da legalidade, impessoalidade, moralidade, publicidade e eficiência (Constituição Federal, artigo 37, caput), evidenciando rigidez e controle dos atos praticados. No entanto, no entendimento de Ribeiro (2016), o Direito Administrativo deve ser entendido a partir de um viés instrumental que lhe permita atender a demandas concretas e cotidianas que influenciam a atividade administrativa. Logo:

Esse caráter cotidiano e concreto resulta em que o direito administrativo e seus arranjos jurídicos respondam também a fatores externos de pressão e conformação, como a premência fiscal, o controle externo, as desigualdades sociais, a competitividade de empresas nacionais no plano global e, especialmente para o que aqui importa, ao desenvolvimento tecnológico (RIBEIRO, 2016, p. 189).

Sendo assim, o conjunto de alterações promovidas pela Emenda Constitucional 85, bem como pela Lei n 13.243/2016 amenizou parcialmente essa rigidez ao permitir, por exemplo, a transposição, o remanejamento ou a transferência de recursos de uma categoria de programação para outra, em se tratando de projetos de ciência, 
tecnologia e inovação, por meio de Decreto Presidencial - mais célere (e não de lei, que é a regra geral), a dispensa de licitação para celebração de contratos de transferência de e licenciamentos, a simplificação da prestação de contas, entre outras.

Em um nível mais geral, pode-se afirmar que o engajamento de atores como agências e fundações de fomento e financiamento, de controle, acompanhamento e avaliação, para a disseminação das novas regras é fundamental, Logo, é necessário que sejam entendidos e internalizados os ditames do MLCTI e de outros marcos legais para que seja possível dar conta das novas formas de interação Universidade-Empresa (U-E). A criação de instrumentos interpretativos como guias e manuais para os usuários torna-se também um imperativo para a efetivação das regras.

Além disso, é preciso que os estados realizem adaptações em suas leis de inovação (COSTA, 2018). Especialmente no que diz respeito às leis estaduais ${ }^{6}$, as adaptações são urgentes e relevantes, tendo em vista a possibilidade de antinomias jurídicas, ou seja, eventuais situações conflitantes e contraditórias entre a regra federal (o novo Marco Legal de CT\&l) e as legislações estaduais. Para alguns estados, entretanto, é necessário que a lei ainda seja criada, ou regulamentada, tendo em vista que nem todos os estados brasileiros haviam implementado suas leis de inovação até data da entrada em vigor do novo MLCTI?

Desse modo, a assimilação do MLCTI pelas universidades e outras ICTs envolve um conjunto mais amplo de fatores, para além arcabouço normativo e do seu conhecimento, tendo em vista que requer também um ambiente institucional no qual a cultura do empreendedorismo, da criatividade e da inovação promova, estimule e valorize a proatividade da academia. Sem a concorrência desses fatores, o novel arcabouço legal terá reduzida efetividade.

\section{CONSIDERAÇŌES FINAIS}

Desde o final dos anos 1990, imprimiu-se no país um conjunto de leis de suporte às ações de C\&T, reforçadas, posteriormente, por arcabouços legais voltados fortemente ao estímulo de atividades de Pesquisa e Desenvolvimento e de Inovação. Com uma concepção mais clara do papel das empresas nesse processo, mas também da própria concepção de Sistema de Inovação, a relação Universidade-Empresa fica ainda mais relevante em países cuja atividade de P\&D se encontra fortemente atrelada às universidades, como é o caso do Brasil. No entendimento de Philippi Jr. (2018), somente poderemos contornar as dificuldades que bloqueiam a interação eficaz entre as universidades e as empresas se forem garantidos três elementos essenciais:

1. Projeto de Estado com continuidade, que se mantenha prioritário no curso de várias administrações sucessivas.

2. Foco em problemas não resolvidos, cujas soluções não existam prontas para serem importadas. 
3. Pessoal capacitado e dedicado nas universidades e centros de P\&D das indústrias.

Sem esses três componentes, fica muito difícil dar saltos tecnológicos. Podemos até ter bom desempenho em vários setores industriais, mas com pouca capacidade competitiva em nível internacional (PHILIPPI JR., 2018, p. 67).

Da parte governamental, é necessário, pois, que seja iniciado um processo de aperfeiçoamento e aprendizado por meio do qual possam ser revistos, testados, corrigidos e equalizados continuamente, não apenas as políticas, a legislação, mas também outros mecanismos e instrumentos necessários à consolidação e evolução do novo arcabouço de CT\&l. É imprescindível que esse processo também contemple a melhoria dos canais de comunicação, para que informações relevantes aos demais atores do SNI possam fluir com mais facilidade, com vistas ao favorecimento das interações, especialmente a tão desejada relação triangular universidade-indústriagoverno. Logo, é necessário que o Estado brasileiro desenvolva capacidades estatais que possam contribuir para que as políticas de CT\&l sejam políticas de Estado e não somente uma bandeira da comunidade científica e de associações e entidades interessadas, bem como atuar no sentido de melhoria das capacidades de governança e coordenação, conforme apontado por estudiosos dessa temática.

O novo Marco Legal de CT\&l constitui uma iniciativa importante para o aperfeiçoamento do SNI brasileiro. Porém, muitas ressalvas devem ser feitas como colocado anteriormente sobre o papel dos agentes de financiamento e de fomento à CT\&I no país e do próprio Direito Administrativo.

No que se refere às universidades e suas possibilidades de interação com o setor produtivo e outros atores que compõem o sistema, entende-se que a nova legislação necessita ser mais bem compreendida no âmbito da gestão universitária, a fim de que normativas internas possam ser reavaliadas para se beneficiar de alterações implementadas pelo novo marco legal. É importante considerar que embora existam exemplos notáveis de envolvimento das universidades públicas com atividades ligadas à cultura do empreendedorismo, da inovação e ações de transferência de tecnologia e propriedade intelectual, tais envolvimentos não são consensuais e não estão generalizados no Brasil. Isso pode ser o resultado de diferentes fatores, como visões estreitas acerca das possibilidades de vinculação da universidade com os diversos setores da sociedade, preferência pela prestação de serviços comunitários e ações voltadas a grupos menos favorecidos e a atividades artísticas e culturais, receio de preterimento das atividades de ensino às atividades de colaboração com empresas e outras entidades não acadêmicas, perda de liberdade de escolha e temas de pesquisa, entre outros fatores. São preocupações que já foram fortemente discutidos em vários estudos e fóruns de debate, apontando que tais temores não têm razão de ser. Por sua vez, o que é verdadeiro são os entraves causados pela falta de recursos financeiros e humanos a serem destinados a essa interação, e, mais grave, a dificuldade de interpretação e implementação das diretrizes do arcabouço legal e regulatório voltado à CT\&l. 
Do ponto de vista das empresas, é interessante também um esforço de compreensão da nova legislação para que possam beneficiar-se de parcerias com universidades, a fim de potencializar seus esforços de Pesquisa, Desenvolvimento e Inovação.

A existência de um arcabouço jurídico para a ciência, tecnologia e inovação e de outras estruturas e mecanismos que estimulem e facilitem a interação entre as instituições científicas e tecnológicas e as empresas é o primeiro passo (mas longe de ser suficiente), para o favorecimento de uma cultura de valorização das atividades criativas, da sua proteção, mas é necessário que essas regras sejam conhecidas e incorporadas às práticas rotineiras da academia. Para tanto, é indispensável a existência de diretrizes internas claras e objetivas, proatividade e comprometimento da direção central, canais de comunicação internos e externos eficientes. Ao favorecer internamente a cultura do empreendedorismo e da inovação, as universidades contribuem para a criação de círculos virtuosos de estímulo à criatividade e proatividade, formando e qualificando recursos humanos com potencial para a replicação desse aprendizado na sociedade.

\footnotetext{
Notas

${ }^{1}$ Carlos Américo Pacheco é o Diretor-presidente do Conselho Técnico-Administrativo da Fundação de Amparo à Pesquisa do Estado de São Paulo (FAPESP).

2 Sobre capacidades estatais, para Evans (2008), devido à crescente importância que ativos intangíveis assumiram no século XXI, especialmente, as ideias, as habilidades e as redes, torna-se crucial a construção de mecanismos e instrumentos que capacitem o Estado para a promoção de novas dinâmicas econômicas e sociais.

${ }^{3}$ Ver em Instituto CODEMEC. Leis Estaduais de Inovação. Disponível em: <http://codemec.org.br/geral/ leis-estaduais-de-inovacao/>; e Em discussão: Revista de audiências públicas do Senado Federal, ano 3, n. 12, setembro de 2012. Disponível em: <https://bit.ly/38nmblO>. Acesso em: Acesso em: 21 nov. 2018.

4 "Este veto impacta diretamente as fundações das universidades, responsáveis, em sua maioria, pelo trâmite financeiro e burocrático da execução dos projetos de parceria. A alteração da Lei 13.243 propunha sanar riscos jurídicos na cobrança de taxas de administração por parte das fundações. O efeito esperado desta proposição era a simplificação da administração dos contratos assinados e a desburocratização e simplificação dos projetos de P,D\&l, que acabam embutindo os custos desta transação em seu bojo (In: ANPEI. Posicionamento Anpei: vetos presidenciais ao Marco Legal de C,T\&I. 14 jan. 2016. Disponível em: $<$ https://bit.ly/38tFX5A>. Acesso em: 21 nov.2018.

${ }^{5}$ Projeto de Lei do Senado n 226, de 2016. Ementa: Altera a Lei no 10.973, de 2 de dezembro de 2004, a Lei no 8.958, de 20 de dezembro de 1994, e a Lei no 8.032, de 12 de abril de 1990, para aprimorar a atuação das ICTs nas atividades de ciência, tecnologia e inovação, e dá outras providências. Ver em: <https://bit.ly/2PeA9Fr>. Acesso em: 21 nov. 2018.

${ }^{6}$ Uma tentativa de contribuir com os desafios dessas novas diretivas no caso do Estado de São Paulo, é o conjunto de artigos que comentam os termos do Decreto voltado à inovação e a sua capacidade de implementação e mudança no patamar do desenvolvimento econômico, social e tecnológico do estado. Ver Monteiro, In: Cadernos de Direito e Inovação n. 1 - "Decreto Paulista de Inovação". Núcleo Jurídico do Observatório da Inovação e Competitividade do Instituto

${ }^{7}$ Até março de 2018 apenas os estados de São Paulo e Minas Gerais já haviam adaptado as suas leis de inovaçãoao novo marco e alguns ainda não haviam criado as suas leis de inovação (cf. informações disponíveis em Izique,C. Marco legal da inovação estreita relação entre instituições científicas e empresas. Agência FAPESP, 02 demarço de 2018. Disponível em: <https://bit.ly/36Bmdvd). Acesso em: 21 nov. 2018.
} 


\section{Referências}

ABIPTI. Código de CT\&I será votado ainda neste ano, diz presidente da CCTCI. 13 set. 2011. Disponível em: < https://bit.ly/2t42hlW>. Acesso em: 21 nov. 2018.

ANPEl. A suspensão da Lei do Bem e o abandono à inovação. 15 mar. 2016. Disponível em: <https://bit.ly/2rsQZaJ>. Acesso em: 20 dez. 2018.

ARBIX, G., CONSONI, F. Inovar para transformar a universidade brasileira. Revista Brasileira de Ciências Sociais, 26(77), 205-224, 2011. Doi http://dx.doi.org/10.1590/S010269092011000300016

AROCENA, R.; SUTZ, J. Looking at national systems of innovation from the South. Industry and Innovation, v. 7, n. 1, p. 55-75, 2000. DOI: https://doi.org/10.1080/713670247

BRASIL. Decreto $n^{\circ}$ 9.283, de 7 de fevereiro de 2018. Disponível em: <http://www.planalto.gov.br/ ccivil_03/_Ato2015-2018/2018/Decreto/D9283.htm >. Acesso em: 21 nov. 2018.

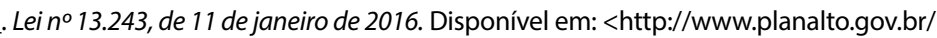
ccivil_03/_Ato2015-2018/2016/Lei/L13243.htm>. Acesso em: 22 ago. 2018.

Emenda Constitucional no 85, de 26 de fevereiro de 2015. Disponível em: <http://www. planalto.gov.br/ccivil_03/Constituicao/Emendas/Emc/emc85.htm>. Acesso em: 22 ago. 2018.

. Constituição da República Federativa do Brasil de 1988. Disponível em: <http://www. planalto.gov.br/ccivil_03/Constituicao/Constituicao.htm>. Acesso em: 12 nov. 2018.

BANDEIRA DE MELLO, C. A. Curso de Direito Administrativo. 33. ed., 3. tir. São Paulo: Malheiros, 2018.

BUAINAIN, A. M.; CORDER, S.; BONACELLI, M. B. M. Capacidades Estatais e Limites da Política de Financiamento à Inovação no Brasil. 2018 (no prelo).

CÂMARA DOS DEPUTADOS. PL 2177/2011. Institui o Código Nacional de Ciência,Tecnologia e Inovação. Disponível em: <https://www.camara.leg.br/proposicoesWeb/ fichadetramitacao?idProposicao=518068>. Acesso em: 27 out. 2018.

CASTRO, A. C. Inovação e Capacidades Estatais Comparadas Brasil, China e Argentina. Texto para Discussão, IPEA, n. 2106, jul. 2015, p. 18. Disponível em: https://bit.ly/2ljEWS9. Acesso em: 15 Jun. 2018.

COSTA, V. 70a Reunião Anual da SBPC debate implementação do Marco Legal da CT\&l em Maceió. Jornal da Ciência, 26 jul. 2018. Disponível em: <https://bit.ly/2k7xD74>. Acesso em: 27 out. 2018.

COUTINHO, D. R.; MOUALLEM, P. S. B. Um Direito para a inovação. Óbices jurídicos e institucionais à inovação no Brasil a partir da noção de 'famílias' de gargalos jurídicoinstitucionais. INOVA \& AÇÃO, JOTA, São Paulo, out. 2018. Disponível em:

$<$ https://bit.ly/2Fkqzho $>$. Acesso em: 15 out. 2018.

EVANS, P. In search of the 21st century developmental state. University of Sussex, Centre for Global Political Economy. Working Paper n. 4, p. 1-22, December 2008. Disponível em: <https:// www.sussex.ac.uk/webteam/gateway/file.php?name=cgpe-wp04-peter-evans.pdf\&site=359>. Acesso em: 05 mar. 2018.

FLORIDA, R. The role of the university: leveraging talent, not technology. Issues in Science and Technology, v. 15, n. 4, Summer 1999. Disponível em: <https://issues.org/florida-3/>. Acesso em: 15 ago. 2018. 
GIMENEZ, A. M. N. As multifaces da relação universidade-sociedade e a construção do conceito de terceira missão. 2017. 329 f. Tese (Doutorado em Política Científica e Tecnológica. Instituto de Geociências, Universidade Estadual de Campinas, Campinas: [s.n.], 2017. Disponível em: <http:// repositorio.unicamp.br/handle/REPOSIP/324319>. Acesso em: 16 abr. 2018.

MAZZUCATO, M.; PENNA, C. The Brazilian Innovation System: A Mission-Oriented Policy Proposal. Avaliação de Programas em CT\&I. Apoio ao Programa Nacional de Ciência (Plataformas de conhecimento). Brasília, DF: Centro de Gestão e Estudos Estratégicos, 2016. p. 9-10. Disponível em: <https://www.cgee.org.br/the-brazilian-innovation-system>. Acesso em: 26 out. 2018.

PACHECO, C. A. Informações fornecidas na palestra intitulada "O desafio das políticas públicas para a inovação no Brasil", ministrada no Departamento de Política Científica e Tecnológica, Instituto de Geociências, da Universidade Estadual de Campinas (DPCT/IG/UNICAMP), em 17 de agosto de 2018.

PACHECO, C. A.; BONACELLI, M. B. M.; FOSS, M. C. FOSS. Políticas de estímulo à demanda por inovação e o Marco Legal de CT\&l. In: COUTINHO, D. R.; FOSS, M. C.; MOUALLEM, P. S. B. (Orgs.). Inovação no Brasil: avanços e desafios jurídicos e institucionais. São Paulo: Blucher, 2017.

PEDROSA, R. C. (Org.). Manual de Legislação em C \& T: Análise dos marcos legais à luz da lei 13.243/2016. Curitiba: GEDA/UFPR, 2018. Disponível em:

PHILIPPI JR, A. et al. USP: Proposta de Agenda para o Futuro. Grupo de Trabalho - A USP Diante dos Desafios do Século XXI. São Paulo: Instituto de Estudos Avançados - IEA/USP, 2018. Disponível em: <https://bit.ly/38E751U>. Acesso em: 12 nov. 2018.

RIBEIRO, L. C. A instrumentalidade do direito administrativo e a regulação de novas tecnologias disruptivas. Revista de Direito Público da Economia - RDPE, Belo Horizonte, ano 14, n. 56, p. 181-204, out./dez. 2016.

SENADO FEDERAL. Projeto de Lei da Câmara ${ }^{\circ}$ 77, de 2015 - Agenda Brasil 2015. Disponível em: $<$ https://www25.senado.leg.br/web/atividade/materias/-/materia/122406>. Acesso em: $20 \mathrm{dez}$. 2018.

SLAUGHTER, S.; LESLIE, L. L. Academic capitalism: Politics, policies, and the entrepreneurial university. Baltimore: The Johns Hopkins University Press, 1997.

SUZIGAN, W.; ALBUQUERQUE. A interação universidades e empresas em perspectiva histórica no Brasil. In: SUZIGAN, W., ALBUQUERQUE, E. M., CARIO, S. A. F. (Eds.). Em Busca da Inovação: Interação Universidade-Empresa no Brasil. Autêntica: Belo Horizonte, MG, Brasil. p. 17-43. 2011.

WIPO. Technology Transfer in Countries in Transition: policy and recommendations. Geneva: WIPO, 2012. <http://www.wipo.int/publications/en/details.jsp?id=4118\&plang=EN>. Acesso em: 27 out. 2018.

Management of academic intellectual property and early stage innovation in countries in transition. Geneva:WIPO, 2010. Disponível em: $<$ http://www.wipo.int/publications/en/details. jsp?id=4117\&plang=EN $>$. Acesso em: 27 out. 2018.

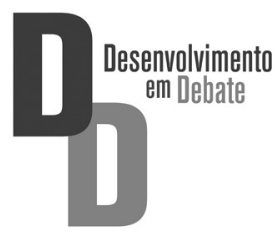

